News

\title{
5th International Symposium on Phytochemicals in Medicine and Food (5-ISPMF) was successfully held
}

\author{
Lingjun $\mathrm{Ma}{ }^{\circledR 1, *}$ \\ ${ }^{1}$ College of Food Science and Nutritional Engineering, National Engineering Research Centre for Fruits and Vegetables Processing, Key \\ Laboratory of Fruits and Vegetables Processing, Ministry of Agriculture, Engineering Research Centre for Fruits and Vegetables Processing, \\ Ministry of Education, China Agricultural University, 100083, Beijing, China
}

\section{ARTICLE INFO}

Article History

Received 30 October 2021

Accepted 1 November 2021

\section{ORGANIZERS}

From August 25 to September 01, and October 18 to 20, 2021, 5th International Symposium on Phytochemicals in Medicine and Food (5-ISPMF) was successfully held as virtual and onsite model. 5ISPMF was sponsored by the International Association of Dietetic Nutrition and Safety (IADNS), Phytochemical Society of Europe (PSE), and Phytochemical Society of Asia (PSA). 5-ISPMF is organized by Nanchang University and University of Vigo. The Organizing Committee was led by Prof. Shaoping Nie (Nanchang University, China) and Prof. Jesús Simal Gándara (University of Vigo, Spain).

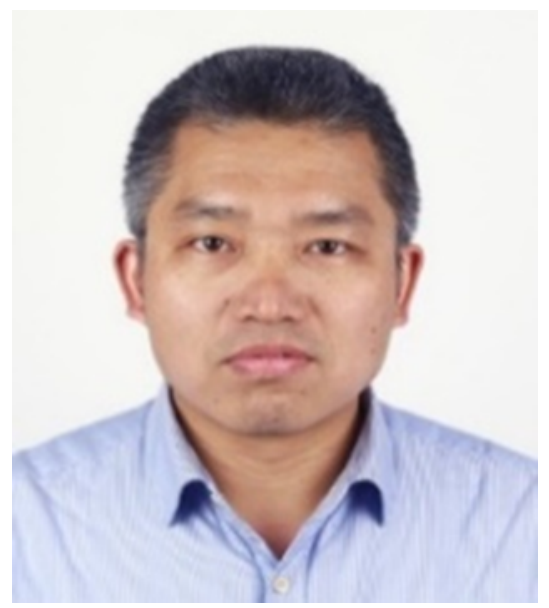

Figure 1 Prof. Shaoping Nie (Nanchang University, China)
(C) 2021 The Author. Publishing services by Visagaa Publishing House This is an open access article distributed under the CC BY-NC 4.0 license (https://creativecommons.org/licenses/by/4.0/).

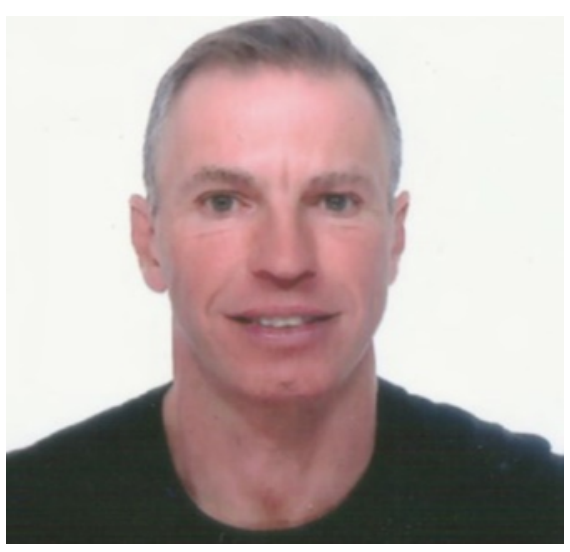

Figure 2 Prof. Jesús Simal Gándara (University of Vigo, Spain)

\section{5-ISPMF OBJECTIVES AND OUTCOMES}

Despite the difficult moment that we are facing, we are fully committed to continue the task of promoting the cooperation and exchange of phytochemicals for food and human health among scientists all over the world. The international scientific committee board of 5-ISPMF assembled an exciting and diverse program, featuring 16 plenary lectures, 52 plenary lectures, 82 invited lectures, 142 oral presentation, 70 short PhD student presentation, 26 short master student presentation, and more than 150 posters.

The Outstanding Contribution Awards were awarded to Prof. Li-Shu Wang (Medical College of Wisconsin, USA), Yoshinori Asakawa (Tokushima Bunri University, Japan), Esra Capanoglu (Istanbul Technical University, Turkey), Jelena B. PopovišDjordjeviš (University of Belgrade, Serbia), Maurizio Battino (Polytechnic University of Marche, Italy), and Mohamed Ali

*Corresponding author. Email: lingjun.ma@cau.edu.cn

Peer review under responsibility of the International Association of Dietetic Nutrition and Safety

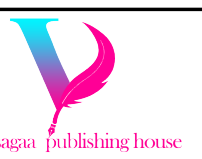


Farag (Cairo University, Egypt), who have helped to organize this conference.
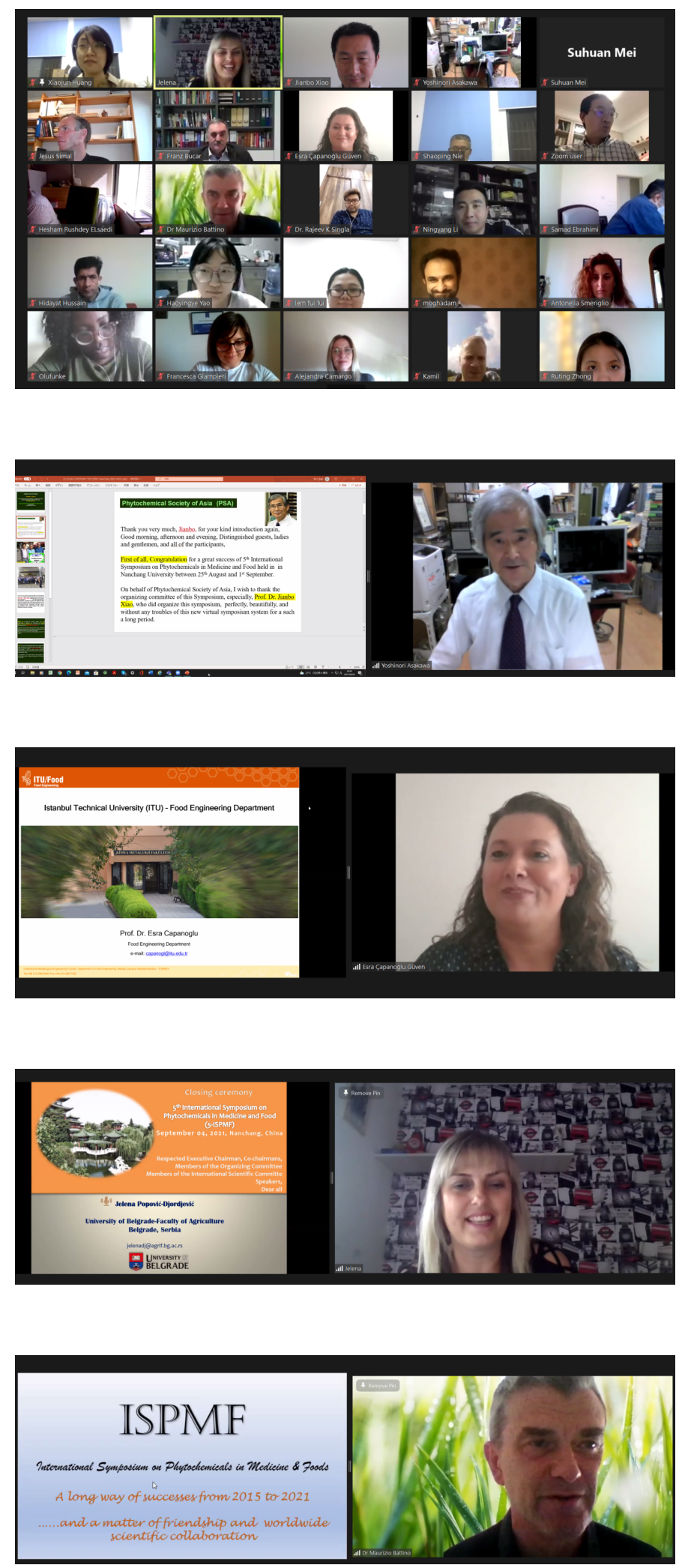
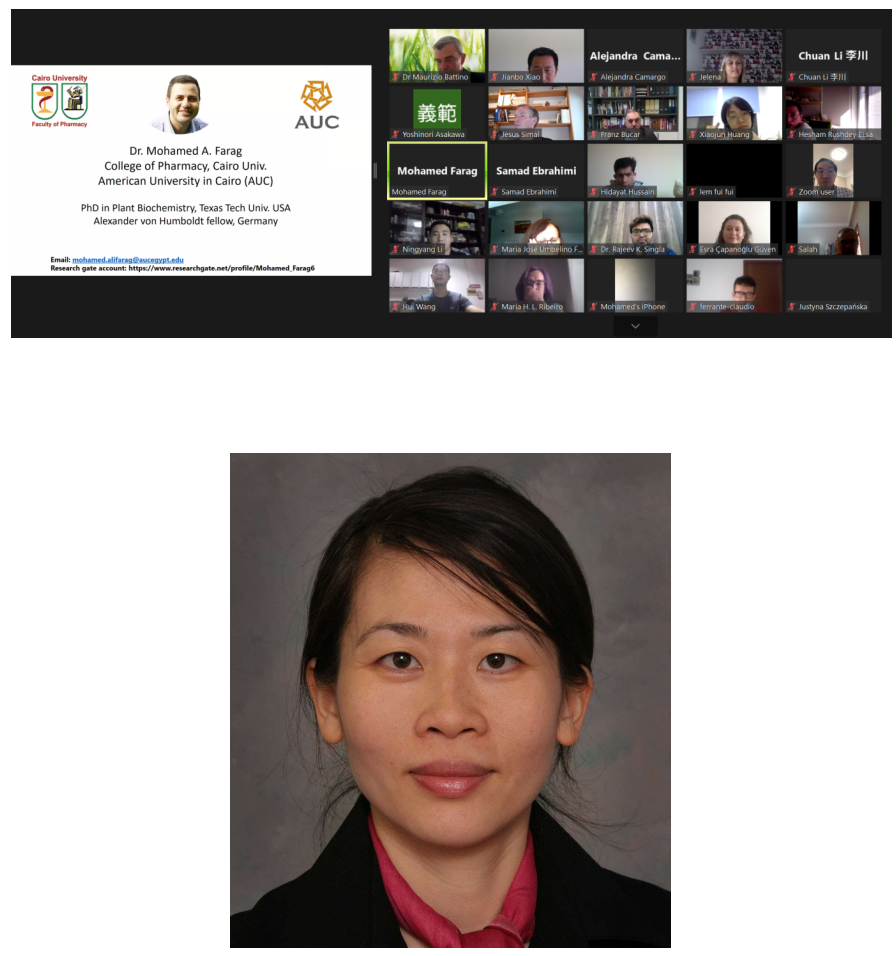

Figure 3 Li-Shu WangMedical College of Wisconsin, USA

\section{PUBLICATION}

5-ISPMF Abstract book published all the accepted 537 abstracts. 5-ISPMF also has obtained the supports form several international journals including Food Chemistry, Marine Drugs, International Journal of Molecular Sciences, Food Chemistry X, and Phytochemsitry Reviews to publish special issues for 5-ISPMF.

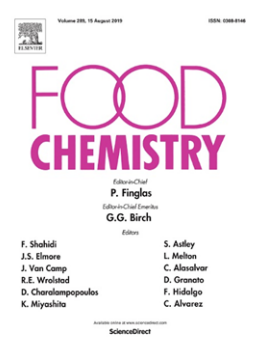

(IF 7.514)

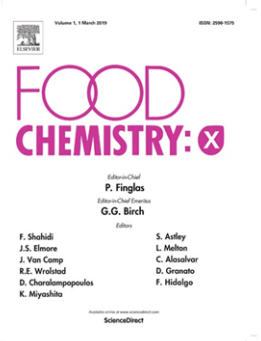

(IF 5.182)

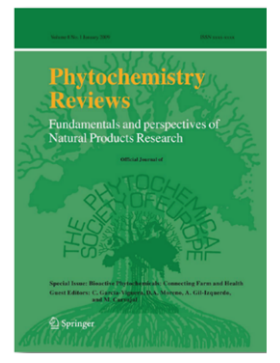

(IF 5.374)

\section{TRULY INTERNATIONAL EVENT}

5-ISPMF was held at international level. This year 5-ISPMF brought together more than 730 delegates from 66 different countries and the foreigners out of China are more than 405 . 